\title{
Gendered participation in the geosciences: 10 years of ERC funding
}

\author{
Claudia Jesus-Rydin, Luis Farina-Busto, and Alexis-Michel Mugabushaka \\ Scientific Department, European Research Council, Brussels, 1210, Belgium
}

Correspondence: Claudia Jesus-Rydin (claudia.jesus-rydin@ec.europa.eu)

Received: 7 February 2020 - Accepted: 26 May 2020 - Published: 2 July 2020

\begin{abstract}
The European Research Council (ERC) marks a new approach to investing in frontier research in Europe. Since its establishment, the ERC has taken numerous actions to tackle imbalances and monitors data from each call. The aim of this paper is to review descriptive statistics of men and women participating in ERC calls in the geosciences. The share of women applying for Starting Grants is on average around $30 \%$, whereas for Consolidator Grants and Advanced Grants the share is around $25 \%$ and $11 \%$ respectively. Success rate analysis shows no significant gender disparities. The paper provides an overview of the ERC peer-review system, discusses results specific to the geosciences compared to national funding and SHE Figures, and concludes with a review of past actions and future goals.
\end{abstract}

\section{Introduction}

The European Research Council (ERC) marks a new approach to investing in frontier research in Europe. The ERC was designed and is governed by the ERC Scientific Council. The Scientific Council is composed of eminent scientists and scholars appointed for a term of up to 4 years, renewable once, to allow a staggered rotation of members. The ERC's mission is to encourage the highest quality research in Europe through competitive funding and to support investigator-driven frontier research across all fields, on the basis of scientific excellence.

Three investigator-driven funding actions designed by the Scientific Council form the core of its activities: (i) Starting Grants (StG), supporting researchers at the early stage of their careers $(2<\mathrm{PhD} \leq 7$ years); (ii) Consolidator Grants (CoG), supporting researchers to consolidate their research programme and team $(7<\mathrm{PhD} \leq 12$ years); and (iii) Advanced Grants (AdG), designed to support outstanding and established researcher leaders in their pursuit of novel ideas.
The ERC funding actions are open to researchers of any nationality who intend to conduct their research activity in any EU Member State ${ }^{1}$ or H2020 Associated Country ${ }^{2}$. Principal investigators may be of any age and nationality and may reside in any country in the world at the time of the application. Principal investigators applying to the ERC are not required to have full-time or permanent positions in Europe. All fields of science are eligible, with no pre-set topics or priorities - blue-sky research.

In just a few years, ERC grant schemes have become a "gold standard" for science in Europe (Myklebust, 2015). ERC grants are the most prestigious in Europe for their support to innovative high-risk research at the frontiers of science and are recognized worldwide as a stamp of excellence (Thomas and Nedeva, 2012; Cuntz, 2016). The scientific performance of ERC grantees is extremely high when compared to the world's largest research funders (Thomson and Kanesarajah, 2017). These grants enjoy global recognition, as the ERC selection standards are praised by the scientific community beyond Europe (European Research Council, 2017). In 2019, 12 non-European countries ${ }^{3}$ signed international agreements allowing short-term visits for their researchers to ERC projects.

Since its creation in 2007, members of the ERC Scientific Council have understood that credibility and visi-

\footnotetext{
${ }^{1}$ List of European Union Member States: Austria, Belgium, Bulgaria, Croatia, Republic of Cyprus, Czech Republic, Denmark, Estonia, Finland, France, Germany, Greece, Hungary, Ireland, Italy, Latvia, Lithuania, Luxembourg, Malta, Netherlands, Poland, Portugal, Romania, Slovakia, Slovenia, Spain, Sweden, and the UK (until the end of all $\mathrm{H} 2020$ actions).

${ }^{2}$ Albania, Armenia, Bosnia and Herzegovina, Faroe Islands, Georgia, Iceland, Israel, Moldova, Montenegro, North Macedonia, Norway, Serbia, Switzerland, Tunisia, Turkey, Ukraine.

${ }^{3}$ List of countries: Argentina, Australia, Brazil, Canada, China, India, Japan, Korea, Mexico, Singapore, South Africa, USA.
} 
bility worldwide, alongside the recognized impact on researchers' careers, carries great responsibility. Since its establishment, the ERC has taken numerous actions (see Appendix A) to tackle imbalances and ensure fair and equal opportunities to all candidates whilst keeping excellence as the sole project evaluation criterion. It collects and analyses data from each call, with particular focus on demographics of applicants. To monitor gender balance in ERC calls, the ERC set up in 2008 a dedicated working group (https://erc.europa.eu/thematic-working-groups/ working-group-gender-balance, last access: 26 June 2020).

The aim of this paper is to review descriptive statistics of men and women's participation in ERC calls in the geosciences. The structure of the paper provides an overview of the ERC peer-review system, results specific to the geosciences (also known as the PE10 panel), discussion of the results, and conclusions on past actions and future goals.

\section{ERC peer-review system}

Proposals are evaluated by selected international peer reviewers, chosen on the basis of their scientific reputation (no self-nomination). Selection is the exclusive responsibility of the Scientific Council. Peer reviewers are in charge of assessing and ranking proposals. Depending on the call budget available, a budgetary cut-off applies to the ranking list and only the highest ranked proposals are offered an ERC grant. For each call, proposals are submitted to 1 of the 25 panels (https://erc.europa.eu/sites/default/ files/document/file/ERC_Panel_structure_2019.pdf, last access: 29 June 2020), each covering a sub-section of one of three domains: Social sciences and Humanities (SH), Life sciences (LS), and Physical and Engineering Sciences (PE). Each ERC evaluation panel is composed of 14 to 18 reviewers. The reviewers in each panel evaluate the proposals on the basis of excellence as the sole criterion. This criterion applies to the evaluation of both the research project and the scientific performance of the principal investigator in conjunction.

Scientific performance (i.e. productivity and impact) is considered an important indicator of scholarly excellence as it plays a role in how reputations are earned, grants acquired, and promotions awarded (Nielsen, 2015). Peer recognition is one of the principal recompenses of the scientific system, as an indication of a researcher's merits to the advancement of scientific knowledge. Even if widely recognized as a service of gatekeeping that is valued in academia, peer review (Marsh et al., 2019) and invited writers in high-impact journals (Conley and Stadmark, 2012) are not immune to critics in terms of potential biases - particularly in relation to gender. Potential disadvantages for women compared with men remain a source of controversy (Bornmann et al., 2007; Marsh et al., 2011). A gender gap in success for receiving national, publicly managed research funding at the European Union level (EU-28) exists. The funding success rate in 2017 in EU-28 was higher for men than for women by 3 percentage points (SHE Figures 2018, 2019).

It is unclear whether differences between success rates of men and women grant applicants are due to systematic gender bias, and there is limited research to assess the result of interventions to mitigate possible gender bias in peer review of grants (Tricco et al., 2017). The mere possibility of gender biases (or any other biases) in grant peer review is a matter of serious concern by funders, as it can compromise the fairness and legitimacy of the evaluation system. Ensuring equal opportunities is a basic principle and its absence can damage the credibility of all the decisions made. Attention to the gender gap in academia, particularly pronounced in the science, technology, engineering, mathematics, and medicine (STEMM) fields, has led many institutions to mandate actions, such as implicit bias training (Gvozdanović and Maes, 2018).

Furthermore, research suggests that the experience of belonging to a group whose abilities are negatively stereotyped may foster the risk of confirming the negative stereotype in academic evaluations and outcomes (Steele and Aronson, 1995). Any suspicion of unfair treatment of or ineptitude by applicants has the potential to increase the stereotype threat effect. Ultimately it could affect the applicant's performance (i.e. during interviews), but also potentially hamper submission rates by individuals who self-identify strongly with a stereotyped group.

The success rate of funding schemes is directly dependent on budget availability versus number of applicants and requested budget for each individual application. An oversubscription of applicants leads to lower success rates. The opposite is also valid: success rates are higher when the budget increases and the number of applicants remains stable (or decreases). In the period from 2008 to 2013, the success rate of women in ERC calls across all fields of sciences (i.e. the 25 evaluation panels) was lower than that of men's by 3.0 percentage points. This difference is the same as the one observed on average in research funding at the European Union level (SHE Figures 2018, 2019). In the last 5 years, however, men and women had practically equal average success rates of nearly $13 \%$ in ERC calls - Table 1 . The share of women's participation in ERC calls, across all research areas, has increased in time. The evolution from the FP7 and H2020 period shows an increase by $8.8 \%$ in the share of women grantees in ERC calls (Table 2). The ERC data presented in this paper do not include Synergy grants (SyG) or Proof of Concept grants (PoC).

Success rate distribution by gender from four national funding bodies in Europe was analysed (Table 3). The country selection was dictated by the access to data through published reports and the possibility of distinguishing natural sciences. The data from the four national funding bodies (Denmark, Germany, Sweden, and the UK) show women with success rates lower than men, varying between 2 and 5 percentage points - this is in line with the data from SHE 
Table 1. Success rates by gender in ERC calls.

\begin{tabular}{|c|c|c|c|}
\hline ERC call year & $\begin{array}{r}\text { Women } \\
\text { success } \\
\text { rate }\end{array}$ & $\begin{array}{r}\text { Men } \\
\text { success } \\
\text { rate }\end{array}$ & Difference $^{c}$ \\
\hline $\begin{array}{l}2008-2013(\mathrm{FP} 7)^{\mathrm{a}} \\
(n=33079)\end{array}$ & $10.0 \%$ & $13.0 \%$ & $-3 \%$ \\
\hline $\begin{array}{l}2014-2018(\mathrm{H} 2020)^{\mathrm{b}} \\
(n=37452)\end{array}$ & $12.7 \%$ & $12.6 \%$ & $0.1 \%$ \\
\hline \multicolumn{4}{|c|}{$\begin{array}{l}\text { a FP7 is the seventh Framework Programme for Research and Technological } \\
\text { Development. It lasted } 7 \text { years (2007-2013). The programme had a total budget } \\
\text { of over EUR } 50 \text { billion, of which the ERC budget is EUR } 7.5 \text { million. }{ }^{b} \text { H2020 } \\
\text { is the eighth Framework Programme for Research and Technological } \\
\text { Development. It is the biggest EU Research and Innovation programme ever, } \\
\text { with nearly EUR } 80 \text { billion in funding available over } 7 \text { years (2014-2020), of } \\
\text { which the ERC budget is EUR } 13 \text { billion. }{ }^{c} \text { Difference = women success } \\
\text { rate - men success rate. A negative difference means men have a higher } \\
\text { success rate than women. }\end{array}$} \\
\hline
\end{tabular}

Table 2. Women's share in ERC calls.

\begin{tabular}{lrrr}
\hline ERC calls & $\begin{array}{r}2008-2013 \\
(\mathrm{FP7})\end{array}$ & $\begin{array}{r}2014-2018 \\
(\mathrm{H} 2020)\end{array}$ & Difference $^{\mathrm{b}}$ \\
& $(n=33079)$ & $(n=37452)$ & \\
\hline Women applicants & $24.1 \%$ & $28.3 \%$ & $4.2 \%$ \\
Women grantees $^{\text {Difference }}{ }^{\mathrm{a}}$ & $19.6 \%$ & $28.4 \%$ & $8.8 \%$ \\
\hline
\end{tabular}

${ }^{\mathrm{a}}$ Difference $=$ share of women grantees - share of women applicants; positive difference means that the share of women grantees is higher than the share of women applicants. ${ }^{\mathrm{b}}$ Differences in share of women applicants and grantees between FP7 and H2020; positive difference means an increase in women's share in the last years (H2020).

Figures mentioned above. Note that these data represent one single year.

\section{Geosciences results}

The geosciences data used in this study refer to proposals evaluated under the ERC "Earth system science" panel (also known as the PE10 panel), which were submitted to three researcher-driven grant schemes $(\mathrm{StG}, \mathrm{CoG}$, and $\mathrm{AdG})$ during the 10-year period of 2009-2018. The ERC geosciences data are analysed in comparison to data of the ERC total (which include all fields of science) and of national funding organizations in Europe.

The "Earth system science" panel (PE10) at the ERC covers a wide range of scientific fields ${ }^{4}$ within the geosciences. During the period of 10 years (2009-2018), 2719 proposals were evaluated in the PE10 panel, of which 328 were funded,

\footnotetext{
${ }^{4}$ Physical geography, geology, geophysics, atmospheric sciences, oceanography, climatology, cryology, ecology, global environmental change, biogeochemical cycles, natural resources management (https://erc.europa.eu/sites/default/files/document/ file/ERC_Panel_structure_2019.pdf, last access: 29 June 2020).
}

corresponding to a total investment of over EUR 657 million in the geosciences.

The gender balance evolution in the geosciences from FP7 to $\mathrm{H} 2020$ is positive (Table 4). In the last 5 years, the share of women applying to the geosciences increased by $3.3 \%$, compared to the first 6 years of the ERC calls. In the same intervals of time, the share of women in the geosciences being awarded an ERC grant increased by $8.2 \%$. Compared to the general results of ERC calls, across all fields of science, the geosciences show a lower share of women applicants by 3.6 percentage points (Tables 2 and 4). The share of women grantees in the geosciences, however, is slightly higher than the ERC average by 1.2 percentage points.

Overall, in the period of 2009-2018, 629 (23\% of the total applicants) women in the geosciences applied to the ERC; of these, 86 (26\% of the total grantees) were awarded.

The next chapters present the participation of women, from geosciences, in the three ERC calls $(\mathrm{StG}, \mathrm{CoG}$, and AdG). Data from these calls provide correlations with different career stages.

\subsection{Starting Grants (StG)}

In 2007, the ERC launched its first call for proposals, with the Starting Grants call attracting more than 9000 candidates. The oversubscription was partly due to the lack of understanding of what ERC proposals were aiming for, which resulted in many proposals being out of scope or ineligible. The success rate of this call was around $3.4 \%$. For these reasons, the data from StG 2007 are not included in this study.

Until 2018 geoscientists were recipients of 135 Starting Grants representing an investment of EUR 209 million. A total of 356 women applied to ERC StG in geosciences, of which 52 were successful, representing a success rate of $14.6 \%$. The ERC average success rate in Starting Grants, including all fields of science, is $12.3 \%$. Figure 1a presents the share of women in ERC StG calls in the last 10 years, both as applicants and grantees, including the absolute number of women applying. The share of women applying yearly to $\mathrm{StG}$ is on average about $30 \%$, with a slight increase of about $4.0 \%$ since 2012 (average $34 \%$ ). Absolute numbers are stable, with an average of about 40 women per year to StG since 2012.

The success rates of both women and men for the same period are presented in Fig. 1b. Since 2009, the success rate of women in $\mathrm{StG}$ in the geosciences has been slightly higher than the one of men, except in 2018. The year 2018 registered a higher absolute number of women applying (i.e. 44 , which is slightly higher than the average of the previous years). Overall, the average success rate for women and men in $\mathrm{StG}$ is $15.4 \%$ and $10.7 \%$ respectively.

The average funding given to geosciences per grant is EUR 1.5 million, with no observed disparity between men and women. 
Table 3. Success rates by gender in European national funding bodies.

\begin{tabular}{|c|c|c|c|c|c|}
\hline Country & $\begin{array}{l}\text { Funding } \\
\text { agency/scheme }\end{array}$ & Year & $\begin{array}{r}\text { Success } \\
\text { rate } \\
\text { women }\end{array}$ & $\begin{array}{r}\text { Success } \\
\text { rate } \\
\text { men }\end{array}$ & Difference $^{\mathrm{a}}$ \\
\hline Denmark $^{b}$ & DFF (Natur og Univers) & 2016 & $6 \%$ & $11 \%$ & $-5 \%$ \\
\hline Sweden ${ }^{c}$ & Swedish Research Council (Science) & 2018 & $26 \%$ & $28 \%$ & $-2 \%$ \\
\hline Germany ${ }^{\mathrm{d}}$ & DFG (Naturwissenschaften) & 2017 & $36.9 \%$ & $39.3 \%$ & $-2.4 \%$ \\
\hline $\mathrm{UK}^{\mathrm{e}}$ & NERC & 2017 & $25 \%$ & $29 \%$ & $-4 \%$ \\
\hline
\end{tabular}

Table 4. Share of women in ERC PE10.

\begin{tabular}{lrrr}
\hline ERC PE10 & $\begin{array}{r}2008-2013(\text { FP7 }) \\
(n=1269)\end{array}$ & $\begin{array}{r}2014-2018(\mathrm{H} 2020) \\
(n=1531)\end{array}$ & Difference $^{\mathrm{a}}$ \\
\hline Women applicants & $20.9 \%$ & $24.2 \%$ & $3.3 \%$ \\
Women grantees & $21.1 \%$ & $29.3 \%$ & $8.2 \%$ \\
Difference $^{\mathrm{b}}$ & $0.2 \%$ & $5.1 \%$ & \\
\hline
\end{tabular}

${ }^{\text {a }}$ Difference between FP7 and H2020 in the share of women as applicants and as grantees; positive difference means an increase in women's share in the last years (H2020). ${ }^{\mathrm{b}}$ Difference $=$ share of women grantees - share of women applicants; positive difference means that the share of women grantees is higher than the share of women applicants.

\subsection{Consolidator Grants (CoG)}

The demand for Starting Grants increased by over $50 \%$ in 2012. Due to this oversubscription, the Starting Grant scheme was split in two: the new ERC Consolidator Grant and the ERC Starting Grant. In 2013 the first Consolidator Grants were launched, enlarging the eligibility window of years after $\mathrm{PhD}$ from 8 to 12 years.

Until 2018 geoscientists were recipients of 83 Consolidator Grants representing an investment of EUR 166 million. A total of 175 women applied for ERC CoG funding, of which 22 were successful, representing a success rate of $12.6 \%$. The ERC average success rate in Consolidator Grants, including all fields of science, is $12.6 \%$. Figure 2a presents the share of women in ERC CoG calls the last 6 years, both as applicants and grantees, including the absolute number of women applying.

The share of women applying yearly to $\mathrm{CoG}$ is on average about $25 \%$. The absolute numbers are stable, with an average of about 25 women per year since 2012 .

The success rates of both women and men for the same period are presented in Fig. 2b. Overall, the success rate of women in $\mathrm{CoG}$ is comparable to the one of men (i.e. $13.5 \%$ and $12.3 \%$ respectively).
The average funding given to geosciences per grant is EUR 2.0 million, with no observed disparity between men and women.

\subsection{Advanced Grants (AdG)}

In the last 10 years, geoscientists were recipients of $110 \mathrm{Ad}-$ vanced Grants representing an investment of EUR 282 million. A total of 98 women applied for ERC AdG funding, of which 13 were successful, representing a success rate of $13.3 \%$. The ERC average success rate in Advanced Grants, including all fields of science, is $12.4 \%$. Figure 3 a presents the share of women in ERC AdG calls the last 6 years, both as applicants and grantees, including the absolute number of women applying.

The share of women applying yearly to AdG is on average about $11 \%$. The absolute numbers are low (an average of about 11 women per year to AdG), which makes statistical analysis less significant.

The success rates of both women and men for the same period are presented in Fig. 3b. As mentioned above, the absolute numbers are too low for statistical analysis. Nevertheless, the overall success rate of women in AdG is comparable to that of men (i.e. $13.2 \%$ and $12.0 \%$ respectively). 

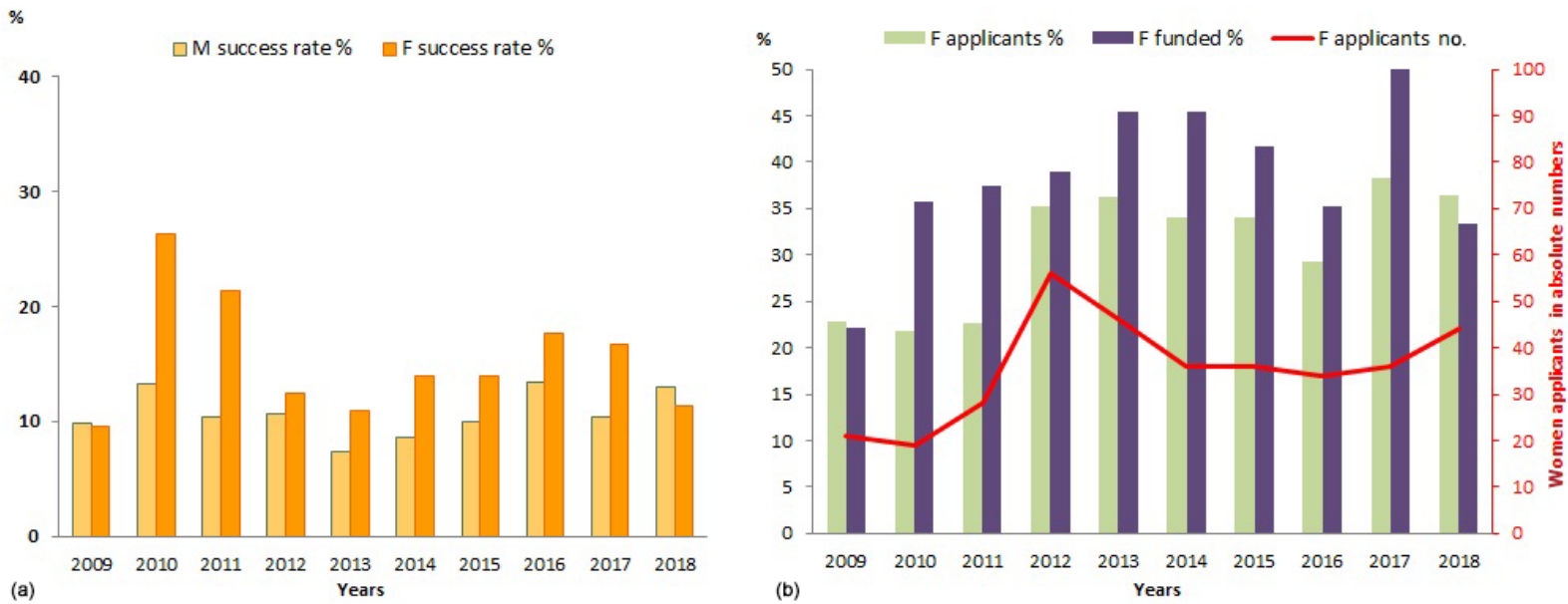

Figure 1. (a) Share of women applicants and grantees, StG (PE10). (b) Success rate of women and men, StG (PE10).
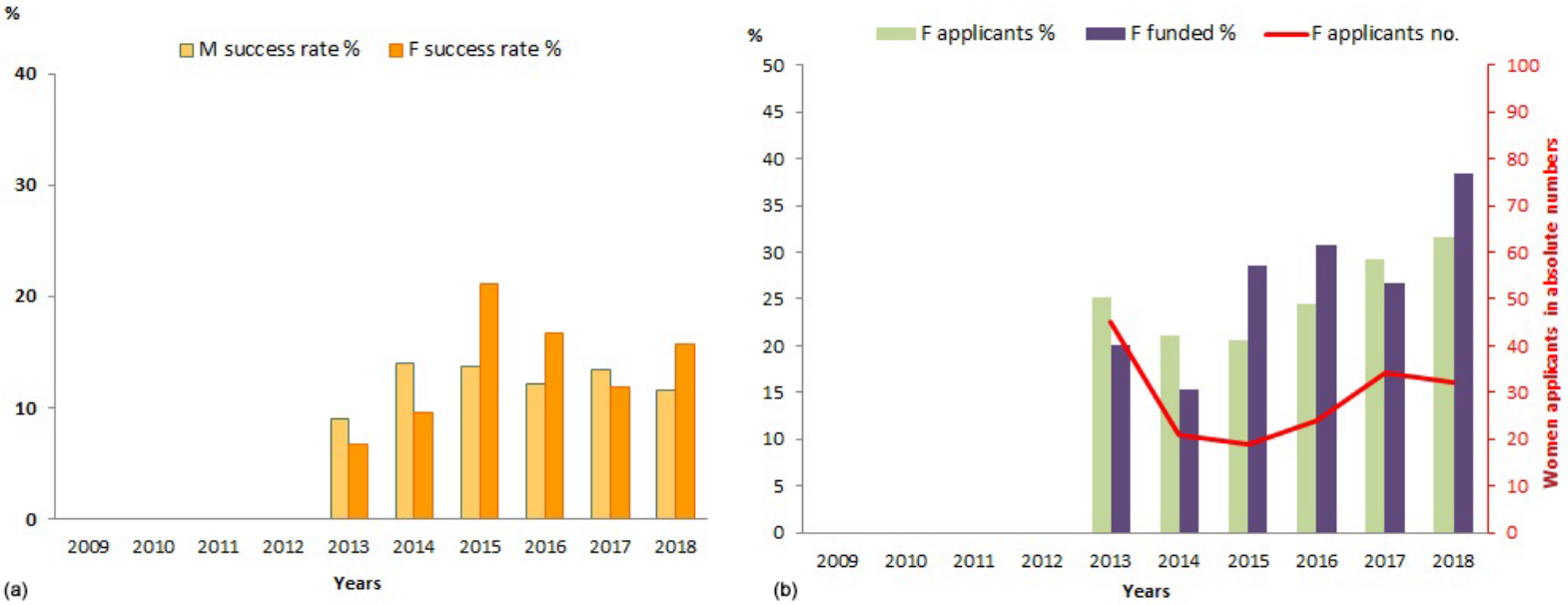

Figure 2. (a) Share of women applicants and grantees, CoG (PE10). (b) Success rate of women and men, CoG (PE10).

The average funding given to geosciences per grant is EUR 2.5 million, with no observed disparity between men and women.

\section{Discussion}

Submission rates to ERC calls in the geosciences for women vary significantly depending on the career stage. Participation of women decreases in granting schemes targeted to higher career grades. The share of women applying for Starting Grants is on average around $30 \%$, whereas for Consolidator Grants and Advanced Grants the share is around $25 \%$ and $11 \%$ respectively. The decrease across career stages observed in the geosciences (PE10) is comparable to those observed in ERC total averages (all fields of science) - Table 5.

A recurrent point of the discussion is whether the share of women applying for ERC calls reflects the share of women in a given field. Such comparative analysis is not easy. Eurostat $t^{5}$ is the centralized European body collecting statistics; however, when it comes to scientific academic fields, those are aggregated in large categories. Geosciences is represented within two major categories: natural sciences and engineering and technology (also known as STEM). According to the SHE Figures (SHE Figures 2018, 2019), based on the Eurostat data, the proportion of women among academic staff in EU-28 in 2016 in STEM fields was $35 \%$ of grade C staff, $28 \%$ of grade B staff, and $15 \%$ of grade A staff.

Assuming a correlation between SHE Figures in STEM for the three academic grades mentioned above (grade C, B, and A) and $\mathrm{StG}, \mathrm{CoG}$, and $\mathrm{AdG}$ calls respectively, the percentage of women applying to the ERC PE10 is slightly lower (on average $3.5 \%$ ) than the share of women in STEM in EU28, particularly in the most senior scheme of AdG. However,

\footnotetext{
${ }^{5}$ Eurostat is the statistical office of the European Union https: //ec.europa.eu/eurostat/, last access: 29 June 2020.
} 

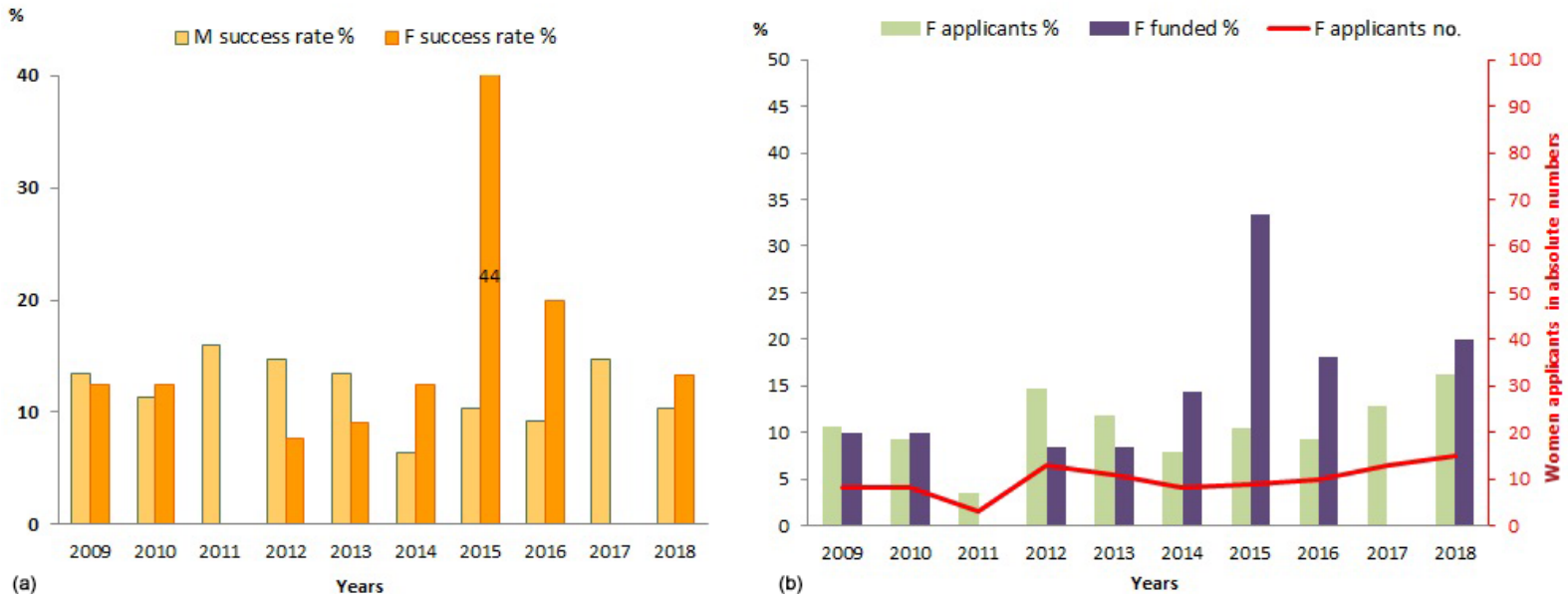

Figure 3. (a) Share of women applicants and grantees, AdG (PE10). (b) Success rate of women and men, AdG (PE10).

Table 5. Difference in the share of women applying to the PE10 and the share of women in STEM.

\begin{tabular}{lrrr}
\hline & $\begin{array}{r}\text { PE10 } \\
\text { women } \\
\text { applying } \\
(\%)\end{array}$ & $\begin{array}{r}\text { SHE } \\
\text { Figures } \\
\text { in STEM }\end{array}$ & Difference* \\
& $(\%)$ & \\
\hline StG (SHE Figures grade C) & 31.4 & 35 & -3.6 \\
CoG (SHE Figures grade B) & 25.5 & 28 & -2.5 \\
AdG (SHE Figures grade A) & 10.7 & 15 & -4.3 \\
\hline
\end{tabular}

* Difference $=$ share of women applying to PE10 - share of women in SHE Figures; negative difference means that the share of women applying in geosciences at ERC is lower than the share of women in STEM in EU-28 (SHE Figures 2018, 2019).

the difference can be due to the low statistical significance of ERC data and/or reflect the uncertainty of the comparison itself (i.e. grant scheme and academic grades not fully matching).

Success rate analysis shows no significant gender disparities, even if there is a slightly higher success rate for women in StG. A point of reflection and discussion is whether the success rate of women should be higher than that of men. Studies indicate that women are more likely to self-censor than men (Think Tank Women and Ambition, 2018) and thus apply for positions only when highly qualified to meet all requirements (Mohr, 2014).

Studies of underrepresented groups claim that proportionality matters in demographics (Kanter, 1977). To benefit from diverse pools, the representation of underrepresented groups should be at least $30 \%$. In addition to group psychology, the importance of proportionality is also mathematical when dealing with low success rates. In $50 \%$ of the PE10 AdG calls, the share of women applying is below 10 in absolute numbers (making up about $11 \%$ of the submissions), with an average success rate in the call of $12 \%$; to have any women funded is an outstanding result.
The ERC data from StG, CoG, and AdG, in a 10-year period, show only minor variation at the different career stages. This observation is in line with claims that disparity in STEM cannot be explained solely by a leaky pipeline (Holmes et al. 2009), as adding more women to one end of the pipeline has not produced significant changes in the percentage of women reaching higher academic levels (in the 10-year period analysed).

The ERC Scientific Council has implemented a set of measures and practices to improve gender equality and fairness as indicated chronologically in Fig. 4. Fair and equal treatment of all candidates has been the focus of attention by the Scientific Council. Each process within the ERC - from creating awareness about the ERC programmes to signing of grant agreements - is designed to give equal opportunities to men and women, following the ERC Scientific Council Gender Equality Plan (https://erc.europa.eu/sites/default/files/document/file/ ERC_ScC_Gender_Equality_Plan_2014-2020.pdf, last access: 29 June 2020).

One of the most innovative measures taken by the ERC was the attribution to all women applicants who had children an extension of the eligibility window. Independent of the formal maternity leave taken (which varies across the EU-28, depending on the national parental laws), women applicants' eligibility window is extended by 18 months per child ${ }^{6}$. The decision was taken to increase equality of opportunities to women facing physical and psychological challenges (before and after giving birth). The ERC recognizes the importance of promoting a balanced society and shared parental duties; therefore, men applicants who have taken paternity leave ${ }^{7}$ are

\footnotetext{
${ }^{6}$ Women are required to submit the birth certificate of the child(ren).

${ }^{7}$ Men are required to submit an official certificate stating the length of the paternity leave taken.
} 


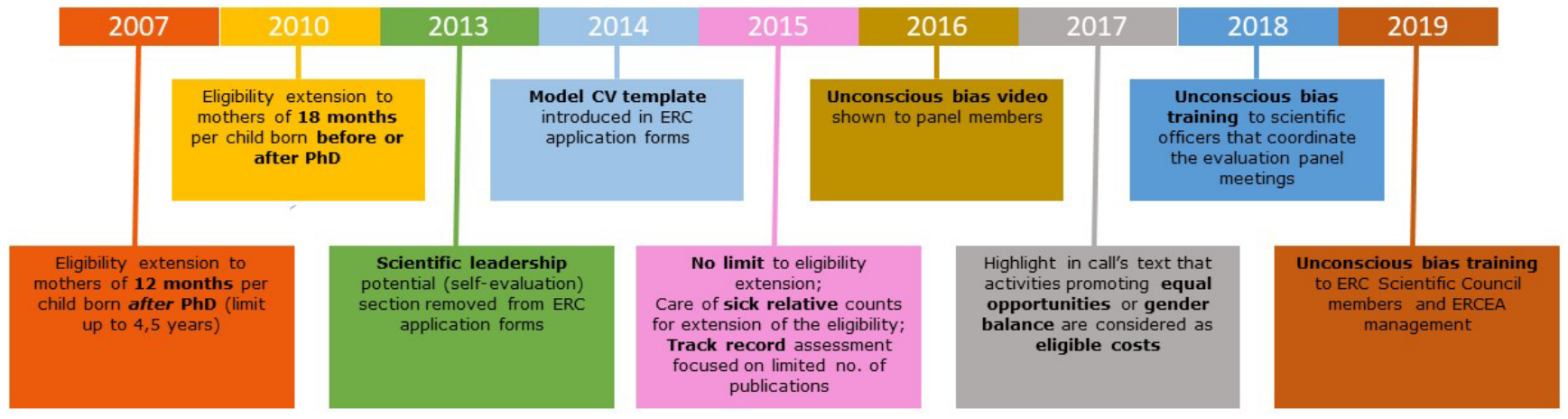

Figure 4. Timeline of measures taken by the ERC to increase gender balance and equal opportunities.

also eligible to request extensions of the eligibility window (equal to the time of leave taken).

\section{Conclusions}

In just over 10 years, the European Research Council has become a powerhouse of science. It has reached very high goals. Firstly, research funded by the ERC has led to major advances at the frontier of knowledge, as the ex post analysis conducted on a random sample of completed projects shows year after year. Overall results of the 2015-2018 exercises show that more than $75 \%$ of ERC projects achieved a breakthrough or a major scientific advance (European Research Council, 2019). Secondly, research funded by the ERC has set clear and inspirational targets for frontier science across Europe, pushing applicants to develop their most ambitious and daring ideas, and not just ask for funding to continue routine work. As such, ERC-supported research contributed significantly to the fact that now Europe is ahead of the US in terms of share of the $1 \%$ most cited scientific articles (Thomson and Kanesarajah, 2017).

Over 120000 publications are reported by ERC projects as a result of the work produced by more than 60000 researchers and other professionals hired in ERC teams. In addition, ERC grantees have been recipients of over 1300 prestigious prizes.

Efforts to tackle gender imbalances and actions to promote equality of opportunities are mainstreamed across the ERC operations. Evaluation based on excellence as a sole criterion, alongside carefully selected and briefed reviewers, are the essentials of the ERC peer-reviewing system. Qualitative and quantitative research results suggest a success of the ERC approach, both in its evaluation model and in its efforts to tackle imbalances.

One possible explanation for the low submission rates by women, especially in AdG, could be the fact that the ERC grants are seen as highly prestigious. Consequently, there may be a fraction of eligible candidates that do not even try to apply - as they may not consider themselves part of an "elite". However, ERC criteria attend to both the innovative character of the project and the track record of the candidate (primarily as regards its adequacy for the proposed project and demonstrated independent and creative thinking). The elite is a prevalent myth that should be replaced instead by a general understanding of the importance given to the innovative character of the scientific ideas of the project.

To increase the participation of women in ERC calls is a general important goal, even if there are many external factors. The ERC is aware of some host institutions that filter their own candidates, thus potentially restricting the diversity in the pool of candidates. It is unclear what the reasoning and motivation are behind such a strategy.

The self-censorship of some candidates may also play a role, encouraged by many ERC myths that continue to circulate in scientific communities. The ERC scientific officers are active in organizing information sessions at major international conferences (e.g. EGU, Goldschmidt and AGU). Those sessions aim at raising awareness, clarifying doubts, and destroying myths.

The authors hope that this paper will also contribute to raising awareness of the ERC efforts and encouraging less obvious candidates to apply. The lower submission rates by women, especially in AdG, remain a focus of attention and actions by the ERC. In addition to the actions listed in the ERC Gender Equality Plan 2014 2020 (https://erc.europa.eu/sites/default/files/document/file/ ERC_ScC_Gender_Equality_Plan_2014-2020.pdf, last access: 29 June 2020), the ERC remains vigilant and open to revising its procedures and adopting new ones when needed (see Fig. 4). 


\section{Appendix A}

Table A1. Actions taken by the ERC scientific council to tackle gender equality.

\begin{tabular}{|c|c|c|}
\hline Year & Action & Comments \\
\hline 2010 & $\begin{array}{l}\text { Extension of eligibility window by } 18 \text { months (women) and no. } \\
\text { of months of parental leave taken (men) per child born before or } \\
\text { after PhD award. The total extension was limited to maximum } \\
\text { of } 4.5 \text { years. }\end{array}$ & $\begin{array}{l}\text { Impact of parental charges on track record is not limited in time; } \\
\text { thus, the link to being prior to the PhD date was removed. } \\
\text { Four and a half years of extension was considered generous. }\end{array}$ \\
\hline 2013 & $\begin{array}{l}\text { Scientific leadership potential (self-evaluation) } \\
\text { section removed. }\end{array}$ & $\begin{array}{l}\text { Scientific leadership section was a subjective source of } \\
\text { cultural imbalances (gender, nationality, support, etc.) and } \\
\text { potential bias. }\end{array}$ \\
\hline 2014 & Model CV template included in application forms. & $\begin{array}{l}\text { Panel members across various scientific domains argued for CV } \\
\text { template to reduce subjectivity of free-style. ERC approved it } \\
\text { with hesitation, as being too prescriptive is not the ERC's } \\
\text { preferred approach. }\end{array}$ \\
\hline 2016 & Video on unconscious bias shown to panel members. & $\begin{array}{l}\text { https://www.youtube.com/watch?v=g978T58gELo, } \\
\text { last access: } 29 \text { June } 2020\end{array}$ \\
\hline 2019 & $\begin{array}{l}\text { Unconscious bias training to (i) all Programme Officers } \\
\text { (ongoing); (ii) ERC Scientific Council (June); (iii) ERC man- } \\
\text { agement (November) }\end{array}$ & \\
\hline
\end{tabular}

* https://erc.europa.eu/sites/default/files/document/file/ERC-Work-Programme-2017.pdf, last access: 29 June 2020 (p. 11). 
Data availability. The data that support the statistical findings of this analysis can be requested from the corresponding author.

Author contributions. CJR designed the work, interpreted data and results and wrote the manuscript. LFB helped analyse the data and correct the manuscript. AMM analysed the bulk of the data and helped in the correction of the manuscript.

The views expressed in this paper are the authors'. They do not necessarily reflect the views or official positions of the European Commission, the European Research Council Executive Agency or the ERC Scientific Council.

Competing interests. The main author of the paper is also one of the five editors of this special issue.

Special issue statement. This article is part of the special issue "Diversity and equality in the geosciences (EGU2019 EOS6.1 \& US4, AGU2018 ED41B, JpGU2019 U-02)". It is a result of the EGU General Assembly 2019, Vienna, Austria, 7-12 April 2019.

Acknowledgements. The authors would like to acknowledge the encouragement and support provided by the ERC management, in particular Martin Penny, the Head of the Unit of Physical Sciences and Engineering.

Review statement. This paper was edited by Katherine Richardson and reviewed by Mary Anne Holmes and Eeva Furman.

\section{References}

Bornmann, L., Mutz, R., and Daniel, H.-D.: Gender Differences in Grant Peer Review: A Meta-Analysis, J. Informetr., 1, 226-238, 2007.

Conley, D. and Stadmark, J.: Gender matters: A call to commission more women writers, Nature, 488, 590, https://doi.org/10.1038/488590a, 2012.

Cuntz, A.: Do Public R\&D Funds Affect the Location Choices of Elite Scientists in Europe?, Res. Evaluat., 25, 383-395, 2016.

Thomas, D. and Nedeva, M.: Characterizing researchers to study research funding agency impacts: The case of the European Research Council's Starting Grants, Res. Evaluat., 21, 257-269, https://doi.org/10.1093/reseval/rvs020, 2012.
European Research Council: ERC - a success story for Europe, available at: https://erc.europa.eu/sites/default/files/document/ file/ERC10_Press_pack.PDF (last access: 23 December 2019), 2017.

European Research Council: Qualitative Evaluation of completed Projects funded by the European Research Council 2018, available at: https://erc.europa.eu/sites/default/files/ document/file/2019-qualitative-evaluation-projects.pdf (last access: 29 June 2020), 2019.

Gvozdanović, J. and Maes, K.: Implicit bias in academia: A challenge to the meritocratic principle and to women's careers - and what to do about it, LERU advice paper, 2018.

Holmes, M. A., OConnell, S., and Dutt, K.: Women in the Geosciences: Practical, Positive Practices Toward Parity, chap. 1, Who Receives a Geoscience Degree?, 11-16, https://doi.org/10.1002/9781119067573, 2015.

Kanter, R. M.: Some Effects on Proportions on Group Life: Skewed Sex Ratios and Responses to Token Women, Am. J. Soc., 82, 965-990, 1977.

Marsh, H. W., Jayasinghe, U. W., and Bond, N. W.: Gender differences in peer reviews of grant applications: A substantivemethodological synergy in support of the null hypothesis model, J. Informetr., 5, 167-180, 2011.

Mohr, T. S.: Harvard Business Review, available at: https://hbr.org/2014/08/ why-women-dont-apply-for-jobs-unless-theyre-100-qualified (last access: 29 June 2020), 2014.

Myklebust, J. P.: Top institutions dominate in fierce ERC grant battle, University World News, available at: https://www. universityworldnews.com/post.php?story $=20151113155204222$ (last access: 29 June 2020), 2015.

Nielsen, M.: Gender inequality and research performance: moving beyond individual-meritocratic explanations of academic advancement, Studies in Higher Education, 41, 2044-2060, https://doi.org/10.1080/03075079.2015.1007945, 2015.

She Figures 2018: European Commission. Directorate-General for Research and Innovation, Luxembourg, Publications Office of the European Union, 2019.

Steele, C. M. and Aronson, J.: Stereotype threat and the intellectual test performance of African-Americans, J. Personal. Soc. Psychol., 69, 797-811, 1995.

Think Tank Women and Ambition: Ambition Professionnelle, regards croisés femmes-hommes, available at: https://www.pwnparis.net/resources/whats-new/research/2382: women-ambition-les-resultats-de-l-etude.html (last access: 29 June 2020), 2018.

Thomson, S. and Kanesarajah, V.: The European Research Council: the first 10 years, London, Clarivate Analytics, 2017.

Tricco, A., Thomas, S., Antony, J., Rios, P., Robson, R., Pattani, R., Ghassemi, M., Sullivan, S., Selvaratnam, I., Tannenbaum, C., and Straus, S.: Strategies to Prevent or Reduce Gender Bias in Peer Review of Research Grants: A Rapid Scoping Review, PLOS ONE, 12, e0169718, https://doi.org/10.1371/journal.pone.0169718, 2017. 